\title{
A ordem e a margem: comportamento disciplinar para Polícia Feminina no Paraná (1977-2000)
}

\author{
Andréa Mazurok Schactae ${ }^{[1]}$
}

\begin{abstract}
Resumo
As policiais femininas, que ingressaram na Polícia Militar do Paraná (PMPR), no final da década de 1970. Para inseri-las na instituição, foi construído um modelo de comportamento feminino pela legislação. Um modelo de policial feminina que deveria ser assumido pelas agentes para elas serem reconhecidas como policiais femininas. Portanto, o objetivo deste artigo é analisar a legislação disciplinar como parte da construção de um padrão de comportamento para a policial feminina, o qual está vinculado à construção de uma identidade para a Polícia Feminina. Observado que a punição do comportamento irregular ou transgressor faz parte do processo de construção do modelo de policial feminina e de policial militar. Para nortear a análise, foram utilizados como referencial teórico Robert Connell, Pierre Bourdieu, Michel Foucault e Joan Scott.
\end{abstract}

Palavras-chave: polícia feminina; identidade; gênero.

\section{El orden y la margen: la conducta disciplinaria de la Policía Femenino en Paraná (1977-2000)}

\section{Resumen}

Las mujeres se unieron al PMPR a finales de 1970. Para insertarlos en la institución se construyó un modelo de comportamiento de la mujer en la ley. Un modelo de mujer policía que debe ser asumida por los agentes para que puedan ser reconocidos como mujeres de la policía. Por lo tanto, el objetivo de este artículo es analizar el derecho disciplinario como parte de la construcción de un patrón de comportamiento de las mujeres en la policía, que está vinculado a la construcción de una identidad para las mujeres policía. Observó que el castigo de la conducta delincuente o irregular es parte del proceso de construcción del modelo de mujer policía y la policía militar. Para guiar el análisis se utilizaron como teórico Robert Connell, Pierre Bourdieu, Michel Foucault y Joan Scott.

Palabras claves: policía femenino, identidad de género.

\section{The order and scope: disciplinary behavior to Police Women in Paraná (1977-2000)}

\begin{abstract}
The Women Police, who joined the PMPR in the late 1970. However, to insert them in the institution was built a model of female behavior by law. A female officer model that should be assumed by the agents for them to be recognized as Police Women. Therefore, the aim of this article is to analyze the disciplinary law as part of the construction of a pattern of behavior for the Police Women, which is linked to the construction of an identity for Women Police. Observed that the punishment of the offender or irregular behavior is part of the process of building the model of Police Women and Military Police. To guide the analysis were used as theoretical Robert Connell, Pierre Bourdieu, Michel Foucault and Joan Scott.
\end{abstract}

Key words: police women; identity; genre.

\section{L'ordre et la marge: le comportement disciplinaire pour la Police féminine au Paraná (1977-2000)}

\section{Résumé}

Résumé : L'insertion de policières dans la Police Militaire du Paraná (PMPR) à la fin des années 1970 a conduit à la construction par la législation d'un modèle de comportement féminin. Ce modèle est alors devenu un réquisit pour que les agentes soient reconnues comme policières. Le but de cet article est d'analyser la législation disciplinaire comme faisant partie de l'élaboration d'un modèle de comportement de la policière, lié à la construction d'une identité pour la police féminine. On observe que la punition du comportement irrégulier ou transgressif fait partie du processus de construction d'un modèle de policière et de police militaire. Pour guider lanalyse, Robert Connell, Pierre Bourdieu, Michel Foucault et Joan Scott ont été utilisés comme référentiel théorique.

Mots-clés: Police féminine ; identité ; genre. 


\section{A "comunidade imaginada" e o feminino: apresentando o objeto ${ }^{1}$}

$\Lambda$ identidade institucional, na Polícia Militar do Estado do Paraná, é constituída por um modelo de "masculinidade hegemônica" (Connell, 1997, p.15-16; 2005, p.185-206). Embora existam distintas masculinidades na instituição, as solelnidades em homenagem aos heróis institucionais e a narrativa da história da instituição constroem uma identidade institucional homogênea que tende a unificar as diferenças constituintes da honra dos agentes. É o poder simbólico herdado e incorporado pelos agentes, percebido nos símbolos presentes nas suas vestimentas - medalhas, insígnias, brasão da unidade policial militar -, que ordena os lugares destinados às masculinidades no espaço da solenidade. Um poder que é definidor da diferença e da igualdade entre os agentes (Bourdieu, 2007; 1998).

Voltando o olhar para o campo da História, observa-se que a polícia é pouco estudada no Brasil. ${ }^{2} \mathrm{O}$ fim da Ditadura Militar e as mudanças no campo acadêmico, na década de 1980, criaram condições para os estudos sobre as polícias. Porém, os pesquisadores Marcos Bretas e André Rosemberg, ao apresentarem um balanço da historiografia da História da Polícia, no Brasil (Bretas e Rosemberg, 2013, p.162-173), destacam que os historiadores tendem a eleger outros objetos de estudo. Vale acrescentar que são raríssimas as pesquisas sobre História da Polícia que utilizam o gênero como categoria de análise. ${ }^{3}$ Assim, este artigo contribui para os estudos no campo, ao observar a polícia como uma instituição constituída por práticas, discursos, símbolos e relações generificadas, bem como pela definição do recorte temporal, pois são raros os estudos de História da Polícia que utilizam como marco temporal as últimas décadas do século XX. ${ }^{4}$

Na década de 1970, a Polícia Militar do Estado do Paraná construiu o padrão de policial feminina, o qual marcava a diferença entre o policial e a policial. Um ideal de policial feminino que deveria ser incorporado pelas mulheres que optaram por vestir a farda, vestimenta símbolo da identificação da instituição policial militar.

O ingresso de mulheres nos quadros da Polícia Militar do Estado do Paraná ocorreu no ano de $1977^{5}$. Em meados da década de 1970, a Polícia Militar do Estado do Paraná iniciou o processo de redação do projeto de criação da Polícia Feminina. No final da década foi definido o texto da Diretriz da Polícia

\footnotetext{
'Esse artigo é parte do quarto capítulo da tese de doutorado (Schactae, 2011). A pesquisa teve financiamento da Capes e do Programa MES/Cuba, e realizou-se entre os anos de 2007 e 2010. Agradeço a todas as pessoas e instituições que colaboraram no processo da pesquisa.

Entres os textos publicados no Brasil sobre estudos das polícias, em diferentes campos do conhecimento, destaca-se a Série Polícia e Sociedade, composta por 11 volumes, publicada pela Editora da Universidade de São Paulo (EDUSP), em conjunto com a Ford Foundation e o Núcleo de Estudos da Violência (NEV-USP). Os livros da coleção foram publicados entre os anos de 2000 e 2003.

${ }^{3}$ Entre os estudos de gênero na polícia militar, no campo da História, ver: Moreira (2007; 2011).

${ }^{4} \mathrm{No}$ Brasil há alguns estudos que analisam o ingresso e a presença de mulheres em instituições policiais militares. Porém, estão vinculados a outros campos do conhecimento. Ver: Soares (2005), Cappelle (2006), Calazans (2003).

${ }^{5}$ ESTADO DO PARANÁ. Decreto-Lei n. 3.238, Lei de criação do Pelotão de Polícia Feminina. Curitiba, 19 de abril de 1977 .
} 
Feminina, o qual oficialmente permaneceu em vigor até a extinção da Polícia Feminina - Diretriz no 076/1979.

As leis e as normas que criaram a Polícia Feminina e instituíram a policial são textos redigidos por sujeitos que possuem o poder de escrever em nome do estado e da Polícia Militar do Estado do Paraná. Esses textos construíram um significado para a presença de mulheres na instituição e um espaço para o feminino na ordem institucional. Ao longo do período marcado pela criação da Polícia Feminina, no ano de 1977, e sua extinção, no ano de 2000 (com a extinção da Polícia Feminina, as agentes foram incorporadas aos quadros que até aquele momento pertenciam aos agentes), as mulheres foram incorporadas à instituição.

Com relação ao ingresso de mulheres na Polícia Militar do Paraná, é preciso considerar, além do processo de reorganização da instituição, ocorrido na década de 1970, as modificações políticas concernentes às questões de gênero, o início do processo de distensão política no Brasil ${ }^{6}$ e as mudanças sociais e culturais do período. A ideia de uma polícia moderna, presente no projeto de reorganização, e o contexto nacional criaram condições para a criação do projeto que resultou na lei de criação da Polícia Feminina no Estado do Paraná. Nada mais "moderno" e "democrático" que uma instituição historicamente masculina aceitar mulheres como agentes.A relação entre o discurso de "modernização", construído pelas polícias militares, e o ingresso de mulheres é apresentada por Rosemeri Moreira (2007), em estudo sobre a criação da Polícia Militar do Estado do Paraná. Também é destacada pelas pesquisadoras Barbara Musumeci Soares e Leonarda Musemeci (2005), ao analisarem o ingresso de mulheres na Polícia Militar do Rio de Janeiro, e por Mônica Carvalho Alves Cappelle (2006, p.165-168), ao estudar a Polícia Feminina em Minas Gerais. Outra característica desse processo, segundo Márcia Esteves Calazans (2003), é a humanização das Polícias Militares.

Vale destacar que a Polícia Feminina foi ao mesmo tempo uma inovação a instituição deixou de ser exclusividade dos homens - e uma afirmação da tradição, pois sua existência reafirma o domínio masculino. É a partir da relação entre a inovação e a tradição que foi instituída a Polícia Militar Feminina como um lugar de contradição. O capital simbólico institucional foi construído para ser incorporado por homens.

Historicamente um espaço masculino, no qual a legislação, o comportamento e a tradição são ferramentas para manter a coerção e a identidade da comunidade imaginada - entendendo comunidade imaginada a partir de Benedict Anderson, para quem "todas as comunidades maiores que as aldeias primordiais onde havia contato cara a cara (...) são imaginadas" (Anderson, 1991, p.26). A presença desse novo agente cria, na instituição, a necessidade de se construir um lugar para o feminino para preservar a identidade institucional.

\footnotetext{
'Para Maria José de Rezende, “(...) os anos de 1975 e 1976 podem ser considerados como um marco importante no processo de distensão política. Também, naquele momento, o grupo de poder da ditadura buscava legitimidade para as suas ações, estratégias e medidas através de seu pretenso ideário de democracia do qual o regime militar se autodenominava, desde o início, propulsor" Rezende (2001, p.174).
} 
E o comportamento da policial feminina se constitui em parte da definição das fronteiras entre o feminino e o masculino na instituição.

Excluídas da memória e da tradição institucional, as quais afirmam um ideal de masculinidade no culto aos heróis, as policiais femininas, assim nomeadas para marcar mais uma diferença nas identificações que existem no espaço institucional, precisam assumir o comportamento feminino definido pela legislação. Para serem reconhecidas como agentes institucionais honradas, deveriam assumir publicamente um comportamento qualificado para uma policial feminina.

A punição do comportamento irregular ou transgressor faz parte do processo de construção do modelo de policial feminina e de policial militar, pois é uma das ferramentas do aparato pedagógico institucional - entre cerimônias, condecorações, cursos de formação, elogios, processos disciplinares que objetiva inscrever nos corpos a norma e a ordem estabelecida. Conforme afirma Michel Foucault, em seu estudo sobre as transformações dos processos de punição, a pena tem com objetivo "procurar corrigir, reeducar, curar" (Foucault, 1989, p. 15). Assim, prossegue o autor,

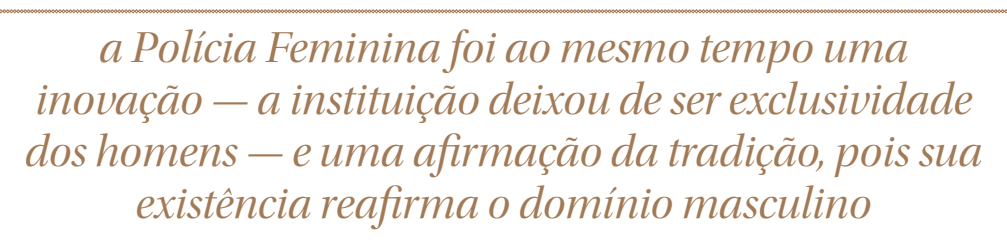

(...) o objeto do crime, aquilo a que se refere à prática penal, foi profundamente modificado: a qualidade, a natureza, a substância, (...). Sob o nome de crimes e delitos, são sempre julgados corretamente os objetos jurídicos definidos pelo Código. Porém julgam-se também as paixões, os instintos, as anomalias, as enfermidades, as inadaptações, os efeitos de meio ambiente ou de hereditariedade (Foucault, 1989, p.21).

O objetivo deste artigo é analisar a legislação disciplinar como parte da construção de um padrão de comportamento para a policial feminina que está vinculado à construção de uma identidade para a Polícia Feminina. Outro elemento construtor desse padrão são as punições aplicadas às policiais. ${ }^{7}$ No entanto, seja no texto da lei ou na aplicação do texto da lei, a instituição objetiva a construção de um comportamento disciplinar feminino. Um ideal de agente que resulta na afirmação da honra institucional e na construção de uma honra para a policial feminina.

7 Um artigo futuro terá como objetivo analisar os processos disciplinares, nos quais as agentes femininas participam como testemunhas e transgressoras. Os processos permitem analisar as tensões entre os comportamentos femininos e a instituições, bem como entre as agentes femininas, tendo em vista que as denúncias de transgressão são efetivadas por agentes femininas, as quais acusam as colegas de possuírem comportamento não compatível com a função de policial feminina. 
Para a seleção das fontes e a construção do objeto foi utilizada a concepção de gênero como categoria, conforme afirmações de Joan Scott (1995, p.71-79). Para a pesquisadora, o gênero permite analisar as construções das relações sociais com base nos significados construídos sobre as diferenças sexuais. Práticas, discursos e símbolos orientam a construção de relações de poder generificadas. Destarte, as diferentes feminilidades e masculinidades são permeadas por relações de poder, as quais são ordenadas pela relação entre os símbolos e suas representações simbólicas; pelas interpretações dos significados dos símbolos expressos nas leis e na história; pelos processos de construção das aparentes permanências na representação binária do gênero; pelas construções das identidades em relação a espaços sociais historicamente delimitados. Assim, a legislação é um discurso, construído pelo Estado - ou instituições que representam o Estado -, que define um ideal de comportamento para a policial feminina, orientando a construção de relações de poder e de diferenças entre o feminino e o masculino, bem como entre as diferentes feminilidades.

O comportamento da policial feminina - construído pela legislação e nos processos institucionais contra as transgressoras - é marcado pela tentativa de controle da sexualidade feminina e pela demarcação da sexualidade de uma policial feminina. Trata-se de uma construção discursiva que oculta os diferentes comportamentos femininos, vivenciados pelas mulheres policiais, constituindo um padrão de comportamento para a policial feminina, uma concepção de comportamento que é norteada pela subjetividade dos oficiais - responsáveis por redigir a legislação e encarregados de julgar as transgressões disciplinares - e das policiais femininas - delatoras e testemunhas nos processos.

As fontes utilizadas neste artigo são: a legislação que define as transgressões, os Boletins Gerais da Polícia Militar do Estado do Paraná (1977-2000), Regulamento Disciplinar do Exército e Regulamento Disciplinar da Polícia Feminina de São Paulo. Esses documentos permitem analisar parte da construção das diferenças entre o masculino e o feminino na Polícia Militar do Estado do Paraná, bem como se constituem em ferramentas construtoras do comportamento-padrão para a policial feminina.

Para a análise das fontes, recorremos aos estudos de Michel Foucault sobre punição, vigilância e disciplina, entendendo que a legislação disciplinar e as punições dirigidas às policiais femininas são constituintes da ordem institucional, que estabelece relações de poder entre o Estado e a Polícia Feminina. Relações que também norteiam a construção de diferenças entre as agentes da Polícia Feminina, bem como entre as Policiais e as outras mulheres, tendo em vista que a conduta de uma policial feminina está vinculada à honra institucional e ao ideal de Policial. Assim, a vigilância e a punição, que visam definir um padrão de comportamento que oriente as atitudes das Policiais nas esferas profissional, pública e privada, também norteiam a construção de uma identidade para a Polícia Feminina. 


\section{Construindo a norma e a ordem: a disciplina militar e a transgressão disciplinar}

Nas primeiras décadas do século XX, o Exército e a Marinha vivenciaram vários movimentos indicativos de que o respeito à disciplina e à hierarquia não estavam incorporados pela tropa, principalmente por praças e tenentes (Castro, 2004, p.301-114; Lanna, 2006, p.313-350; McCann, 2007, p.232-233). Em seus estudos sobre a masculinidade nas instituições militares brasileiras no início do século XX, Peter Beattie apresenta alguns indícios do processo de construção de uma concepção de disciplina militar, que consolida o serviço militar com uma atividade viril. Os estudos do autor vinculam o ideal de militar, que se firma no início do século XX no Brasil, à influência das ideias europeias - principalmente dos exércitos francês e alemão - sobre organização militar e comportamento sexual. Para ele, essas mudanças na disciplina alteram a identidade do militar, pois os quartéis, lugares até então identificados com a marginalidade e com valores opostos aos da família, deveriam constituir-se em lugares de homens honrados. Os apontamentos do autor indicam que a invenção de uma concepção de disciplina nas instituições armadas brasileiras nas primeiras décadas do século XX é central ao processo de construção de uma masculinidade controlada nos quartéis. O recrutamento obrigatório e a construção da ideia de família militar fortaleceram a formação da identidade militar viril e responsável pela Pátria (Beattie, 2004, p.269-299).

Os estudos de Frank D. McCann também revelam que a preocupação com o comportamento e a disciplina norteou as ações dos Comandos das Forças Armadas e do Governo Federal nas primeiras décadas do século XX. A disciplina dos tenentes, dos sargentos, dos cabos e dos soltados foi criticada por militares franceses e norte-americanos (McCann, 2007).

A comparação entre os textos dos regulamentos dos anos de 1942, 1977, 1984 e 2002 permite constatar que as ideias de disciplina, de hierarquia, de transgressão, de punição, de recompensa, de comportamento, de honra e de família militar estão presentes em todos eles. É necessário destacar que os significados dessas ideias estão vinculados aos diferentes contextos vividos pela instituição militar ao longo do século XX, bem como à subjetividade dos agentes que possuem o poder simbólico de interpretar os textos das leis. Porém, os regulamentos apontam que na primeira metade do século XX se estabeleceu a norma disciplinar do Exército, e a disciplina se constituiu em um atributo da honra militar. Assim, considerando que as instituições militares se estabeleceram como um espaço de homens honrados, ao longo do século XX existe uma tendência da reprodução do comportamento identificador do militar.

Historicamente, as instituições militares são percebidas como espaços reprodutores de valores e categorias sociais. A disciplina, a hierarquia, a formação nas escolas militares, o culto aos heróis e a história institucional produzem e reproduzem o modelo de comportamento dos agentes militares que orienta as atitudes do militar dentro e fora dos quartéis, principalmente daqueles que possuem maior poder hierárquico. Assim, a Polícia Militar do Paraná do final 
do século XX também é um espaço que tende à construção e reprodução de um comportamento, o qual é herdado do Exército Brasileiro e da história da instituição policial militar.

Atualmente, a norma disciplinar que estabelece o comportamento do policial militar na Polícia Militar do Estado do Paraná é o Regulamento disciplinar do Exército (RDE). No ano de 1969, o governo militar decreta que todas as polícias militares deveriam adotar um regulamento disciplinar semelhante ao do Exército. Porém, na década de 1950, o Código da Polícia Militar do Estado do Paraná, em seu art. $1^{\circ}$, indicava o RDE como regulamento norteador da disciplina dos agentes. ${ }^{8}$ Consultados os Boletins Gerais, do início do século XX, e os textos memorialistas, escritos por um capitão da instituição, percebe-se que, já na primeira década do século $\mathrm{XX}$, a instituição adotou vários regulamentos do Exército, inclusive o coronel comandante era um oficial do Exército. Diante desses indícios, é bem provável que o RDE tenha sido adotado pela polícia militar do Estado do Paraná no início do século XX.

A definição do que é irregular é central para estabelecer-se a norma, uma lógica que é percebida no texto do Regulamento disciplinar do Exército do ano de 1977. Da apresentação da sua finalidade consta a afirmação de que o objetivo da lei disciplinar é "especificar as transgressões disciplinares e estabelecer normas relativas a punições disciplinares, comportamento militar das praças, recursos e recompensas". ${ }^{\prime 9}$ Objetivando identificar a norma existente na Polícia Militar do Paraná, no final do século XX, quando foi criado o Pelotão de Polícia Feminina, foi utilizado neste estudo o texto do Regulamento disciplinar do Exército do ano de 1977.

A definição pela legislação dos significados de disciplina militar e de transgressão disciplinar estabelece os princípios da ordem institucional. No Regulamento disciplinar do Exército, disciplina militar é definida como:

A rigorosa observância e o acatamento integral das leis, regulamentos, normas e disposições, traduzindo-se pelo perfeito cumprimento do dever por parte de todos e de cada um dos componentes do organismo militar.

São manifestações essenciais de disciplina:

1) a correção de atitudes;

2) a obediência pronta às ordens dos superiores hierárquicos;

3) a dedicação integral ao serviço;

4) a colaboração espontânea para a disciplina coletiva e a eficiência da instituição.

A disciplina e o respeito à hierarquia devem ser mantidos permanentemente pelos militares na ativa e na inatividade. As ordens devem ser prontamente cumpridas. $^{10}$

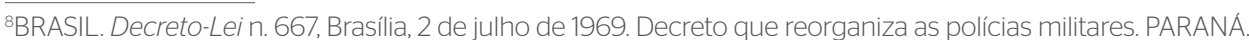
Lei n. 1943. Curitiba, 23 de junho de 1954. Rosa (1998a; 1998b; 1999; 2000; 2001; 2002; 2004).

'BRASIL. Decreto n. 79.985, de 19 de junho de 1977.

${ }^{10 B R A S I L}$. Decreto n. 79.985, de 19 de junho de 1977. Regulamento disciplinar do Exército. Diário Oficial [da] República Federativa do Brasil, Brasília, DF, 20 jul. 1977. Disponível em: http://www.senado.gov.br/legislação>. Acesso em: 15 set. 2009. 
Ser um militar disciplinado significa aceitar e nortear suas atitudes pela legislação, bem como respeitar a hierarquia. Além do mais, a lei recomenda que todo militar que souber de uma ação contrária à disciplina militar deve informar o superior hierárquico; caso contrário, também está infringindo a ordem. "A disciplina faz funcionar um poder relacional que se autossustenta por seus próprios mecanismos e substitui o brilho das manifestações pelo jogo ininterrupto dos olhares calculados" (Foucault, 1989, p.158-159).

A esfera de ação do poder da disciplina militar rompe com as fronteiras da atividade militar e alcança outras esferas sociais - públicas e privadas. Ao estabelecer o que é disciplina, o regulamento institui uma rede de vigilância, tornando todos responsáveis pela ordem institucional e com o poder de controlar o comportamento dos agentes.

O comportamento do militar - seus gestos, sua vestimenta, seu corte de cabelo, seu tom de voz, sua postura, sua sexualidade, seu respeito à hierarquia, à moralidade, aos bons costumes - é construído pela disciplina do corpo, pois é nele que se inscreve a honra institucional - discurso marcado pela tradição e pela legislação, o qual orienta práticas. O conjunto de atitudes, valores e ideias vinculados à identidade do militar torna visível a honra do agente e da instituição. A disciplina militar é uma ferramenta de inscrição da identidade nos corpos dos agentes, mas também de construção e de reprodução do comportamento militar e da ordem institucional.

A transgressão afeta a ordem e atinge a honra (pessoal e/ou coletiva), pois a indisciplina é um ato desonroso, que traz vergonha para a instituição e para aqueles que vestem a farda da instituição. A definição de transgressão disciplinar é necessária para afirmar o modelo de comportamento. Segundo o regulamento, a transgressão disciplinar é:

(...) qualquer violação dos preceitos de ética, dos deveres e das obrigações militares, na sua manifestação elementar e simples. (...)

São transgressões disciplinares:

1) Todas as ações ou omissões contrárias à disciplina militar especificadas (...);

2) Todas as ações ou omissões, não especificadas na relação de transgressões (...), nem qualificadas como crime nas leis penais brasileiras, que afetem a honra pessoal, o pundonor militar, o decoro da classe e outras prescrições estabelecidas no Estatuto dos Militares, leis e regulamentos, bem como aquelas praticadas contra normas e ordens de serviço emanadas de autoridade competente. ${ }^{11}$

Essa definição generalizante possibilita que múltiplas atitudes dos agentes institucionais possam ser qualificadas como transgressoras. Principalmente porque a legislação permite que elas sejam caracterizadas como ofensivas

"BRASIL. Decreto n. 79.985, de 19 de junho de 1977. Regulamento disciplinar do Exército. Diário Oficial [da] República Federativa do Brasil, Brasília, DF, 20 jul. 1977. Disponível em: http://www.senado.gov.br/legislação. Acesso em: 15 set. 2009. 
à "honra pessoal, o pundonor militar e o decoro da classe". ${ }^{12}$ Os significados das expressões pundonor militar e decoro de classe indicam a existência de uma honra e uma moral coletiva vinculadas à identidade institucional. As fronteiras entre a honra pessoal e a coletiva na instituição militar são difíceis de definir, pois o culto aos heróis, a história institucional (oficial) e a ideia de família militar - outra expressão que é norteadora da construção do comportamento disciplinado - dificultam a delimitação entre o pessoal e o coletivo no espaço institucional.

A ideia de que a instituição é uma família militar — entendendo que a família tem um papel de reprodução da ordem, assim como a história institucional - permite vincular o comportamento militar à moral tradicional, afirmadora do domínio masculino, bem como estabelecer inúmeras transgressões como ofensivas à honra. Romper com a disciplina é um ato desonroso que atinge a honra da família militar. Dessa forma, toda transgressão disciplinar afeta a honra institucional, pois rompe com a normalidade. Contudo, isso não significa que a instituição qualifique toda transgressão como ofensiva à honra.

\section{Romper com a disciplina é um ato desonroso que atinge a honra da família militar. Toda transgressão disciplinar afeta a honra institucional, pois rompe com a normalidade.}

A identificação da instituição militar como "família militar" está presente nos regulamentos disciplinares do Exército e representa uma ordem simbólica que legitima o poder de vigilância dos agentes, independentemente da posição hierárquica. Todos os agentes são responsáveis por cuidar do nome da instituição e por manter a normalidade. Enquanto a vigilância cabe a todos, o poder de julgar as transgressões e de distribuir as honrarias pertence aos comandantes (modelos de homens honrados, viris e heterossexuais).

A punição e a recompensa distribuídas aos agentes representam um padrão de comportamento. Qualificar e tornar públicas as condutas dos agentes tanto as recompensas como as punições - são encenações que afirmam o ideal de comportamento do grupo. Ao se tornar pública a qualificação de um comportamento - honrado ou despossuído de honra - ele contribui para afirmação da honra institucional.

No início das atividades do dia, diante da tropa formada para a cerimônia de hastear a Bandeira Nacional, é realizada a leitura do Boletim Interno, no qual são publicados os atos do Comando, entre os quais os elogios - para as praças e os oficiais - e as punições das praças - a punição dos oficiais é publicada em Boletim Reservado, destinado aos círculos dos oficiais -, para

12BRASIL. Decreto n. 79.985, de 19 de junho de 1977. Regulamento Disciplinar do Exército. Diário Oficial [da] República Federativa do Brasil, Brasília, DF, 20 jul. 1977. Disponível em: http://www.senado.gov.br/legislação>. Acesso em: 15 set. 2009 . 
conhecimento de todos os agentes institucionais. Essa prática é uma encenação de universalidade, pois indica que toda a instituição tomou conhecimento dos atos que se tornaram públicos e a assinatura do comandante no final do boletim torna legítimo seu texto.

A classificação do comportamento das praças, segundo o Regulamento disciplinar do Exército, "espelha o seu procedimento civil e militar".13 Assim, classificar o comportamento é parte da constituição da hierarquia da honra, a qual é marcada pela seguinte classificação comportamental: excepcional, ótima, boa, insuficiente e má.

A finalidade da punição, segundo o texto do Regulamento disciplinar do Exército, é "preservação da disciplina e deve ter em vista o benefício educativo ao punido e à coletividade a que ele pertence". ${ }^{14}$ Esse esclarecimento indica que $\mathrm{o}$ ato de punir objetiva afirmar a norma e servir de ferramenta pedagógica - educativa e exemplar. Punir é construir e afirmar a normalidade, conforme sustenta Michel Foucault, e o conjunto de preceitos que forma a normalidade "são sinais de filiação a um corpo social homogêneo, mas que têm em si mesmos um papel de classificação, de hierarquização e de distribuição de lugares" (Foucault, 1989, p.164). Assim, a construção da norma e da ordem também é construtora das diferenças.

O ingresso de mulheres na Polícia Militar do Estado do Paraná criou na instituição a necessidade de construir uma norma para o comportamento da policial que afirmasse a ordem estabelecida e definisse as diferenças entre o masculino e o feminino, bem como entre as policiais e as outras mulheres.

Herdeiros de uma tradição marcada por um ideal de masculinidade hegemônica, os oficiais responsáveis pela redação da legislação criaram um modelo de comportamento para a policial, o qual também é ativado no perfil das candidatas à corporação. Ao construir um padrão de comportamento para a policial, a instituição afirmou as diferenças de gênero.

A construção da normatização do comportamento das policiais femininas foi norteada pelo regulamento disciplinar adotado pela Polícia Militar do Estado do Paraná e pela legislação da Polícia Feminina, redigida a partir das concepções de comportamento feminino compartilhadas pelos redatores da legislação. Assim, as policiais tinham dois regulamentos disciplinares: o Regulamento disciplinar do Exército e o Regulamento da Polícia Feminina.

O corpo da mulher policial - o cabelo, a sexualidade, o modo de sentar e de caminhar, o tom de voz, o condicionamento físico - deveria estar de acordo com o texto da norma disciplinar da Polícia Feminina. O padrão de conduta feminino, empregando a expressão utilizada na legislação, construiu mais uma diferença entre o policial militar e a policial, além das já apresentadas — o

\footnotetext{
${ }^{13 B R A S I L . ~ D e c r e t o ~ n . ~ 79.985, ~ d e ~} 19$ de junho de 1977. Regulamento disciplinar do Exército. Diário Oficial [da] República Federativa do Brasil, Brasília, DF, 20 jul. 1977. Disponível em: http://www.senado.gov.br/legislação. Acesso em: 15 set. 2009.

14 BRASIL. Decreto n. 79.985, de 19 de junho de 1977. Regulamento disciplinar do Exército. Diário Oficial [da] República Federativa do Brasil, Brasília, DF, 20 jul. 1977. Disponível em: http://www.senado.gov.br/legislação. Acesso em: 15 set. 2009.
} 
quartel, a farda, a nomenclatura, o currículo, as atividades de policiamento, a hierarquia -, uma concepção de honra feminina. Portanto, a conduta honrada construída para a policial feminina a diferenciava do policial militar, bem como das outras mulheres.

O estabelecimento de um comportamento identificador da policial, vinculado à honra institucional e à construção de uma honra feminina, foi iniciado no ano de 1977 e concluído no ano de 1979. Nesse período, foi redigida a legislação que definiu a norma que organizou a Polícia Feminina e que permaneceu em vigor até o ano 2000. Analisando a legislação da Polícia Militar do Paraná, observa-se que entre os anos de 1977 e 2000 o ideal de policial feminina não sofreu alterações significativas.

No dia 8 de novembro de 1977, foram publicadas algumas "instruções complementares referentes ao Pelotão de Polícia Feminina,", ${ }^{15}$ entre as quais estavam as que se referiam aos deveres e obrigações da policial. Nesse documento, o Comando afirmou que as alunas sargentos tinham os mesmos deveres e obrigações que os alunos sargentos. No dia 24 de novembro, foi publicado outro documento destinado às alunas sargentos, no qual o comandante alterou seu posicionamento e estabeleceu normas e procedimentos específicos para tais alunas. ${ }^{16}$ Ficou estabelecido que, além das transgressões disciplinares e das normas determinadas pelo Regulamento disciplinar do Exército, às quais estavam sujeitos todos os agentes institucionais, para as policiais foram estabelecidas transgressões disciplinares específicas. A existência de uma normatização diferente, segundo afirmação contida na regulamentação, foi "em função das peculiaridades [do] novo Quadro". ${ }^{17}$ Assim, ficou estabelecido como transgressões disciplinares femininas:

a. comprometer-se irregularmente com encargos de família;

b. fazer-se acompanhar, quando uniformizada, salvo se estiver em missão de serviço;

c. frequentar, uniformizada, café, bares ou estabelecimentos similares salvo em missão de serviço;

d. frequentar, quando uniformizada, cinemas, teatros, casa de diversão ou similares, salvo em missão de serviço;

e. fumar quando de serviço, estando uniformizada ou não;

f. manter relacionamento de amizade com pessoas de duvidosa reputação;

g. receber visita nos postos de serviço ou interior do aquartelamento;

h. usar, quando uniformizada, cabelos compridos, de cor diferente do natural, com penteados exagerados, perucas, maquiagem excessiva, unhas longas ou com verniz de cor. ${ }^{18}$

O controle sobre o corpo da policial - a moral identificada nas ações do corpo, que passa a representar a instituição e um modelo de policial feminina - é central nas transgressões citadas. Ao moldar o corpo e inscrever nele a

15POLICIA MILITAR DO ESTADO DO PARANÁ, Boletim Geral n. 208, 1977. ${ }^{16}$ POLICIA MILITAR DO ESTADO DO PARANÁ, Boletim Geral n. 219, 1977. 
lei da instituição, a Polícia Militar construía a policial - um corpo em que é inscrito um comportamento identificador de uma identidade feminina e que também incorpora a instituição policial militar -, marcada por diferenças de gênero e por contradições. Uma construção que afirma o proibido para estabelecer a norma; um corpo feminino em uma ordem masculina.

Comparando-se o regulamento da Polícia Paranaense com o da Polícia Paulista, observamos que são semelhantes, indicando a reprodução de uma categoria já estabelecida. ${ }^{19}$ Conforme destaca Rosemeri Moreira, a polícia feminina paulista se constituiu em modelo para as polícias femininas criadas nas décadas de 1970 e 1980 no Brasil (Moreira, 2007).

No "Regulamento do Quadro Especial de Policiamento Feminino da Polícia Militar do Estado de São Paulo", em vigor no ano de 1977, identifica-se que, além de proibir que as policiais fumassem quando em serviço, conforme na citação, há outras transgressões disciplinares semelhantes ou iguais às especificadas para a Polícia Feminina do Paraná, que são as seguintes:

\section{Uma construção que afirma o proibido para estabelecer a norma; um corpo feminino em uma ordem masculina.}

- Frequentar, uniformizadas, cafés ou bares.

- Ingerir bebidas alcoólicas em bares, cafés ou similares.

- Frequentar, quando uniformizada, boates - lugares assemelhados, cinemas, teatros ou casas de diversões.

- Frequentar, uniformizada, restaurantes sem permissão. (...)

- Fazer-se acompanhar, quando uniformizada, de pessoas estranhas à Corporação, salvo se estiver de serviço. (...)

- Apresentar-se em público com farda alterada, desabotoada, desfalcada de peças, sem cobertura, com canetas, lapiseiras, correntes ou qualquer objeto pendente, joias, enfeites, óculos não permitidos ou carregando volumes. (...)

- Usar, quando uniformizada, cabelos cumpridos, de cor diferente da natural, com penteados exagerados, perucas, maquilagem excessiva, unhas longas, ou com verniz extravagante. (...)..$^{20}$

As outras transgressões disciplinares da Polícia Paulista são semelhantes às especificadas no Regulamento disciplinar do Exército. A proximidade entre as transgressões previstas para as policiais de São Paulo e para as do Paraná revelam que o ideal de mulher policial construído pela Polícia Paulista foi

\footnotetext{
19 Vale lembrar que as mulheres ingressaram na Polícia Paulista na década de 1950 e no início da década de 1970 foram incluídas na Polícia Militar de São Paulo. A historiadora Rosemeri Moreira analisou a construção da Polícia Feminina Paulista. Ver: Moreira (2011)

20SÃO PAULO. Decreto n. 52.655, 12 fev. 1971. Regulamento disciplinar do Quadro Especial do Policiamento Feminino da Polícia Militar de São Paulo. Diário Oficial do Estado de São Paulo. São Paulo, SP, 13 fev. 1971. Disponivel em: http://www.al.sp.gov.br/legislacao/norma.do?id= 81950. Acesso em: 18 ago. 2009.
} 
apropriado pela Polícia Paranaense. O silêncio da legislação paranaense quanto ao consumo de bebida alcoólica pelas mulheres policiais militares, fardadas ou à paisana, possibilita duas interpretações: a) as mulheres policiais poderiam consumir bebida alcoólica em lugares públicos, desde que se vestissem à paisana; b) a instituição entende que uma mulher de moral e bons costumes não consome bebida alcoólica - nos processos se identifica que o consumo de bebida alcoólica pelas mulheres policiais foi qualificado como conduta irregular. Considerando-se a preocupação da instituição com o controle do corpo da policial fora da atividade de trabalho, estando ela fardada ou à paisana, é bem provável que a instituição entenda como desnecessárias determinadas especificações, como no caso da bebida alcoólica, pois historicamente são qualificadas como ofensivas à moral e aos bons costumes femininos.

Na comparação entre as transgressões disciplinares especificadas no Regulamento disciplinar do Exército do ano de 1977 e as previstas no código destinado às policiais, fica evidente o controle sobre os lugares proibidos a elas. Como há um silêncio sobre os permitidos, é possível afirmar que as mercearias, os supermercados, as padarias, as escolas, os açougues, as igrejas, entre outros, são lugares permitidos, pois representam uma extensão do espaço doméstico. Embora sejam locais públicos, estão vinculados ao espaço doméstico, que historicamente pertence ao feminino.

Diferentemente das determinações para as mulheres, aos homens é permitida a circulação em todos os espaços públicos. Observa-se que, na legislação, não há referência específica ao controle dos lugares onde os policiais podem circular, o que é indicativo de que a eles era permitido frequentar, mesmo uniformizados, bares, cafés, cinemas, teatros e outros locais. Ainda que o Regulamento disciplinar do Exército também estabeleça um controle sobre o corpo do policial militar, aos policiais militares é permitido frequentar todos os lugares públicos, uniformizados ou à paisana, desde que esses lugares não atinjam a moral, os bons costumes e a honra institucional. Ao proibir as policiais de frequentar determinados lugares públicos, a instituição impõe limites ao movimento das agentes nos lugares públicos e reproduz uma ordem que exclui as mulheres de boa conduta dos espaços públicos.

O texto da legislação estabelece uma ordem que reproduz o privado como feminino e o público como masculino. Ainda que a instituição seja um espaço masculino que permitiu o ingresso de mulheres, a legislação que constrói o lugar do feminino na instituição é um instrumento de afirmação de um ideal de comportamento feminino e de reprodução de uma ordem masculina. Ao impor limites ao corpo da policial, o organismo preserva a honra institucional, pois a má conduta de uma agente atinge e mancha o nome da instituição Polícia Militar e Polícia Feminina - diante dos que estão fora dela e também afeta a honra e a moral da agente.

Sobre o ato de fumar, também o Regulamento disciplinar do Exército estabelece um controle: aos homens, era permitido quando em serviço, porém com restrições, enquanto para as mulheres foi proibido, pois, historicamente, as mulheres de boa conduta não fumam em público e não frequentam bares 
e casas noturnas. Em seu estudo sobre mulheres trabalhadoras e sexualidade no Brasil da primeira metade do século XX, a historiadora Margareth Rago afirma que "pelo menos até a década de sessenta, acreditava-se que a mulher, sendo feita para o casamento e para maternidade, não deveria fumar em público ou comparecer a bares e boates desacompanhada (...)" (Rago, 2008, p.604). Analisando-se a legislação da Polícia Feminina do ano de 1977, observa-se que o discurso da lei, elaborado pelos oficiais da instituição, tende a afirmar um ideal de feminilidade que coloca as mulheres policiais sob a tutela da instituição, que objetiva controlar a vida privada das agentes.

Além das transgressões citadas, a norma publicada no dia 24 de novembro de 1977 definiu também orientações vinculadas ao matrimônio, à maternidade e à apresentação pessoal, especificamente sobre o padrão do cabelo para a policial feminina. ${ }^{21}$ Sobre o matrimônio, ficou definido que a policial que "amasiasse ou contraísse matrimônio durante o seu funcionamento",22 seria punida com o desligamento do Curso de Formação de Sargentos. Como a lei não especificou quando as policiais poderiam constituir família, supõe-se que fosse após o término do curso. Na orientação sobre a policial gestante, foram adotadas as regulamentações do Estatuto dos funcionários civis do Estado do ano de $1970,{ }^{23}$ e sobre o uso da farda pela policial grávida e as atividades dela na instituição, foi estabelecido que no quinto mês de gestação a policial deixaria de usar a farda e passaria às atividades burocráticas. ${ }^{24} \mathrm{O}$ pequeno espaço de tempo entre as duas publicações da Polícia Militar do Estado do Paraná (dias 8 e 24 de novembro de 1977) e os diferentes posicionamentos do Comando (na primeira publicação, ele afirmou a igualdade na formação dos homens e das mulheres; e, na segunda, estabeleceu a diferença) expressa a dificuldade deste em construir o agente feminino - uma contradição dentro da instituição. Tais documentos estabelecem que o casamento, os relacionamentos afetivos e a maternidade são significantes da honra da policial feminina.

Orientada por um ideal feminino que estabelecia o casamento e a maternidade como destino para mulheres honradas, a Polícia Militar foi construindo um padrão de comportamento para as policiais, ao mesmo tempo que construiu um padrão visual para a agente. Além do comportamento ideal, as

\footnotetext{
21POLICIA MILITAR DO ESTADO DO PARANÁ, Boletim Geral n. 219, 1977. 22POLICIA MILITAR DO ESTADO DO PARANÁ, Boletim Geral n. 208, 1977.

${ }^{23}$ Art. 236 - A funcionária gestante é concedida, mediante inspeção médica, licença por três meses, com percepção do vencimento ou remuneração e demais vantagens legais.

§ 1 - Salvo prescrição médica em contrário, a licença será concedida a partir do início do oitavo mês de gestação.

§ 2 - Quando houver necessidade de preservar a saúde do recém-nascido, a licença poderá ser prorrogada por três meses.

§ $3^{\circ}$ - A funcionária gestante, quando em serviço de natureza braçal, terá direito a ser aproveitada em função compatível com o seu estado, a contar do quinto mês de gestação, sem prejuízo do direito à licença de que trata este artigo." PARANÁ. Lei n. 6.174, Estatuto dos Funcionários Civis do Estado. Curitiba, 20 nov. 1970

24POLICIA MILITAR DO ESTADO DO PARANÁ, Boletim Geral n. 208, 1977.
} 
policiais deveriam possuir uma “boa apresentação pessoal".25 Objetivando normatizar a aparência das policiais, os dois documentos mencionados dedicam três parágrafos a orientações sobre as formas de usar o cabelo, o que indica uma preocupação significativa com o cabelo das mulheres, conforme constatação de Rosemeri Moreira (2007, p.114), em sua pesquisa sobre a Polícia Feminina do Paraná. A pesquisadora afirma que o cabelo é o principal sinal da feminilidade, sendo um sinal de virilidade o cabelo curto.

No Regulamento disciplinar do Exército, não há referência sobre o padrão de cabelo dos homens. Porém, o visual do militar é algo já estabelecido, isto é, a norma está incorporada às práticas institucionais, sendo desnecessária sua determinação em lei. A tradição e a memória institucionais naturalizaram determinadas atitudes e o visual do militar como identificadores de valores institucionais, sendo desnecessária a atualização da norma escrita que data do ano de 1916. Uma das marcas identificadoras do militar e da masculinidade, o padrão do corte do cabelo militar motivou o Comando do Exército a publicar, no ano de 1995, uma diretriz para substituir a norma do início do século XX. ${ }^{26}$ Os motivos que moveram o Comando do Exército a reafirmar essa norma são desconhecidos.

Como as policiais estão fora da tradição e da memória militar — historicamente, as mulheres pertencem a outros espaços, embora a partir da década de 1970 elas passem a ocupar um amplo espaço no mercado de trabalho, os espaços de poder continuam sendo ocupados por homens, principalmente no que se refere ao poder das instituições armadas - , a instituição policial militar necessitava construir uma norma para o cabelo da mulher policial militar. Todavia, em outras instituições militares essa normatização do visual da mulher militar pode ser diferente. Observando-se algumas imagens de mulheres militares publicadas nas últimas décadas do século XX no Brasil, verifica-se que o padrão de cabelo é curto ou comprido e preso. Em Cuba, no mesmo período, nas imagens, as mulheres das instituições armadas usam principalmente cabelos compridos e soltos, sendo raras as imagens em que elas estejam com os cabelos presos. ${ }^{27}$ Isso indica que a construção dos padrões visuais da mulher militar não é homogênea, assim como o padrão de comportamento feminino exigido das militares.

A legislação do ano de 1979, que substituiu a de 1977, tende a manter o comportamento já estabelecido e apresenta uma justificativa para a existência de uma disciplina específica para as policiais femininas a partir das "peculiaridades da organização" ${ }^{28}$ - utilizando o termo presente na legislação. Considerando-se a

\footnotetext{
${ }^{25}$ POLICIA MILITAR DO ESTADO DO PARANÁ. Boletim Geral n. 208, 1977; POLICIA MILITAR DO ESTADO DO PARANÁ. Boletim Geral n. 219, 1977.

${ }^{26}$ Conforme informações contidas na Portaria Ministerial n. 310, de 29 de maio de 1995, a legislação que regulamentava o corte de cabelo dos militares datada do ano de 1916. MINISTÉRIO DO MINISTÉRIO DO EXÉRCITO. Portaria n. 310, de 29 de maio de 1995. Normas para corte de cabelo e uso de barba e bigode por oficiais e praças do Exército. Disponível em: <http://www. militar.com.br/modules>. Acesso em: 18 nov. 2010.

${ }^{27}$ Foram consultadas as revistas Bohemia e Mujeres, publicadas em Cuba, no período que compreende as décadas de 1970 e 1980. As revistas estão nos arquivos da Biblioteca Provincial de Havana e na Casa do Historiador, em Holguín.

${ }^{28}$ POLICIA MILITAR DO ESTADO DO PARANÁ. Diretriz n. O76/79. Curitiba, 1979.
} 
legislação, legalmente, o padrão de comportamento da policial feminina manteve-se praticamente inalterado até a extinção da Polícia Feminina.

A legislação do ano de 1979, que substituiu a de 1977, tende a manter o comportamento já estabelecido e apresenta uma justificativa para a existência de uma disciplina específica para as policiais femininas a partir das "peculiaridades da organização" ${ }^{29}$ - utilizando o termo presente na legislação. Considerando-se a legislação, legalmente, o padrão de comportamento da policial feminina manteve-se praticamente inalterado até a extinção da Polícia Feminina.

Objetivando definir um padrão de comportamento que correspondesse às ditas especificidades, a instituição estabeleceu as seguintes transgressões disciplinares:

(1) Comprometer-se irregularmente com encargos de família, principalmente se solteira; [sem grifo no original]

(2) Manter relacionamentos íntimos não recomendáveis ou socialmente reprováveis com superiores, pares ou subordinados;

(3) Fazer-se acompanhar, quando uniformizada, por elementos do sexo masculino, salvo se estiver em missão ou serviço;

(4) Frequentar, uniformizada, cafés, bares ou estabelecimentos similares, salvo em missão ou serviço;

(5) Frequentar, quanto uniformizada, cinemas, teatros, casas de diversões ou similares, salvo em missão ou serviço;

(6) Fumar quando em serviço, instrução ou no interior do aquartelamento, na presença de outrem, estando uniformizada ou não;

(7) Manter relacionamento de amizade ou de intimidade com pessoas de reputação duvidosa;

(8) Receber visitas nos postos de serviço ou no interior do aquartelamento;

(9) Usar, quando uniformizada, perucas, maquiagem excessiva, unhas longas ou com verniz de cores extravagantes;

(10) Invocar circunstâncias de matrimônio ou encargos de família para eximirse das obrigações funcionais.

São consideradas transgressões disciplinares passíveis de licenciamento a Bem da Disciplina aquelas que afetam a honra pessoal, o pundonor militar e em particular o da organização da Polícia Feminina ou que venha ainda de encontro aos padrões de conduta fixada na presente Diretriz. ${ }^{30}$

Comparando as transgressões disciplinares do ano de 1979 com as citadas anteriormente, verifica-se que a solteirice se constituiu em agravante da transgressão. Na legislação de 1977, não foi estabelecido vínculo entre as obrigações familiares e a condição de solteira. O posicionamento do organismo revela a construção moral feminina para as policiais solteiras, que qualifica como irregular a maternidade fora do casamento, bem como os relacionamentos irregulares das policiais com policiais militares. Assim, apesar de as casadas, desquitadas e divorciadas apresentarem, para os legisladores militares, uma

29POLICIA MILITAR DO ESTADO DO PARANÁ. Diretriz n. O76/79. Curitiba, 1979.

30POLICIA MILITAR DO ESTADO DO PARANÁ. Diretriz n. 076/79. Curitiba, 1979. 
moral diferente, porque estavam desprovidas da pureza, que é identificada no corpo da mulher solteira honrada, elas também deveriam assumir uma postura norteada pela moral e pelos bons costumes. O controle da instituição sobre os relacionamentos amorosos, as amizades e o matrimônio das policiais, bem como sobre a opção pela maternidade fora do casamento, constituiu-se como definidor do comportamento feminino idealizado para a policial.

O controle sobre a vida privada das policiais é reafirmado no decorrer do texto da Diretriz, principalmente sobre a temática do matrimônio referente a elas. Foi estabelecido que a policial deveria solicitar ao comando uma autorização para o matrimônio com antecedência de 60 dias. No decorrer desse período, seria realizada, segundo a legislação, "uma investigação social sobre a vida pregressa do noivo da solicitante". ${ }^{31}$ Essa exigência é uma exclusividade da legislação da Polícia Feminina, pois não há referência de investigação sobre a vida da noiva do policial que solicitasse autorização para o casamento. Embora o Código da PMPR também determine que o praça homem solicite autorização para o matrimônio, não há o estabelecimento de um prazo. Somente para os oficiais está definido o prazo de dez dias para apresentação ao comando de documento que comprove o matrimônio. ${ }^{32}$ Essa norma permanece em vigor.

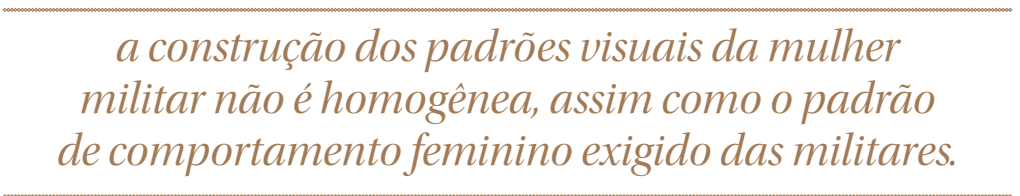

Também foi estabelecido que a Policial somente poderia "contrair matrimônio após um período de 2 (dois) anos, contados da data de inclusão na Corporação" ${ }^{33}$ A ampliação desse período em comparação com o especificado na legislação do ano de 1977 é mais um indicativo do controle da instituição sobre a sexualidade das policiais. Assim, a instituição tende a reproduzir uma construção histórica de pureza sexual feminina que culturalmente está vinculada à honra masculina. Quando rompem com o ideal de pureza construído pela legislação, as policiais atingem a honra institucional e afetam o ideal de policial.

O modelo ideal de policial resulta da construção de uma ordem moral diferenciada para homens e mulheres. A conduta da policial é descrita a partir de conceitos historicamente construídos - bons costumes, relacionamentos socialmente reprováveis, honra e conduta moral —, cujo significado pertence a contextos específicos. Os processos de julgamento das transgressões disciplinares permitem identificar como a instituição, ou melhor, os homens que representam a instituição e que redigiram a legislação significaram esses

31POLICIA MILITAR DO ESTADO DO PARANÁ. Diretriz n. O76/79. Curitiba, 1979

32ESTADO DO PARANA. Lei n. 1943, Código da Polícia Militar do Paraná. Curitiba, 23 de junho de 1954.

${ }^{33}$ ESTADO DO PARANÁ. Lei n. 1943, Código da Polícia Militar do Paraná. Curitiba, 23 de junho de 1954 
conceitos identificadores do comportamento feminino idealizado, ao qualificar as atitudes irregulares das transgressoras.

O controle expresso na legislação sobre a sexualidade, os relacionamentos das mulheres policiais e os locais públicos frequentados pelas policiais em uma sociedade em que a participação das mulheres é crescente revelam que o modelo ideal de comportamento feminino que permeia a legislação da Polícia Feminina não corresponde aos múltiplos comportamentos que as mulheres assuiram na década de 1970. Vale destacar que, embora exista um silêncio quanto aos lugares que as policiais podem frequentar quando despidas da pele que identifica a Polícia Feminina — a farda —, a legislação delega ao comandante da Polícia Feminina esse controle.

O controle sobre o comportamento das Policiais foi o dispositivo que o organismo encontrou para diminuir as contradições entre o ideal de feminilidade e sua vivência pelas diferentes mulheres que ingressaram na Polícia Militar Feminina. Conforme afirmações do texto da Diretriz de 1979,

\section{(...) o Comandante da organização de Polícia Feminina deve ter como preocupação permanente o acompanhamento e avaliação de todas as atividades das policiais-militares, não só naquelas de caráter operacional ou funcional, mas também nas de caráter pri- vado, que possa repercutir negativamente à Corporação como um todo. Neste particular, deve ser preocupação permanente: 0 local de moradia e com quem vive, a conduta civil; os relaciona- mentos com pessoas militares ou não, atividades complemen- tares, diversões, e outros padrões de conduta. ${ }^{34}$}

O poder do comandante de controlar o dia a dia dessas mulheres policiais dentro e fora do espaço das atividades policiais é indicativo de que se instituiu uma rede de vigilância e controle. Como ele não poderia estar em todas as partes, cada agente institucional tornava-se os seus olhos. Todos, policiais mulheres e homens, foram legalmente instituídos como responsáveis pelo controle da conduta dos agentes institucionais, principalmente desses agentes diferentes - as policiais femininas — , que ocupavam um espaço indefinido no organismo e que representavam a imagem maternal da instituição.

No ano de 1983, o Comando Geral publicou a única alteração ocorrida na Diretriz do ano de 1979 antes da extinção da Polícia Feminina, que se refere à "permissão para contrair matrimônio"35 Com a alteração, passou a ser observado o texto do Código da PMPR, que veio a regulamentar o matrimônio das mulheres. ${ }^{36}$

A preocupação em controlar o matrimônio das policiais, nos primeiros anos da presença feminina na Polícia Militar, é um elemento que marcou as

${ }^{34}$ POLICIA MILITAR DO ESTADO DO PARANÁ. Diretriz n. O76/79. Curitiba, 1979.

35POLICIA MILITAR DO ESTADO DO PARANÁ. Boletim Geral n. 149, 1983.

${ }^{36}$ “Art. 111. O oficial em atividade que contrair matrimônio, comunicará a realização do ato ao Comando Geral, no prazo de dez dias, exibindo a respectiva certidão.

Parágrafo único. A praça só poderá assumir tal compromisso mediante prévia autorização do mesmo Comando." PARANÁ. Lei n. 1.943, Código da Polícia Militar do Paraná. Curitiba, 23 de junho de 1954. 
diferenças entre o ideal de policial militar e o de policial feminino. A preocupação do organismo com o comportamento das policiais está vinculada à reconstrução da imagem institucional, mas também indica que a instituição a Força Armada do Estado do Paraná - é o estado atuando como reprodutor de valores tradicionais ligados ao ideal de família e de comportamento feminino, bem como reproduzindo a divisão dos papéis e dos lugares do feminino e do masculino na ordem institucional.

No ano de 1986, em um relatório solicitado pelo Comando do Policiamento do Interior (CPI) sobre a Polícia Feminina - aos comandos de Ponta Grossa, Londrina, Maringá e Cascavel - , um dos comandantes do Interior apresentou entre os pontos negativos os problemas morais vinculados aos relacionamentos entre policiais militares e policiais femininas, utilizando a nomenclatura constante no documento. O comandante também apresenta a gravidez das mulheres casadas como um problema para a instituição. Além do mais, a fragilidade física e psíquica, a falta de coragem, entre outras constatações, são apresentadas como problemáticas, indicando que a presença de mulheres na Polícia Militar causou transtornos administrativos e poucos benefícios para a instituição. ${ }^{37}$

O envolvimento íntimo, qualificado como não recomendável, entre as policiais e os policiais rompia com os ideais de moral feminina e de família. E o casamento entre um policial masculino e um feminino estabelecia a ordem. Todavia, o casamento entre praças e oficiais é um problema para a hierarquia institucional, pois, como esposas, as praças passam a circular em reuniões e clubes destinados aos oficiais.

Embora a presença das mulheres no organismo policial seja uma contradição à ordem institucional, a legislação e o posicionamento do Comando tendem a reafirmar a ordem simbólica institucional ao legitimar o controle sobre a sexualidade das policiais e, principalmente, os vínculos estabelecidos entre oficiais e praças da Polícia Feminina. Esse controle foi reafirmado por uma publicação do comandante geral no ano de 1999. Ele recomendou aos comandantes das Organizações Policiais Militares para que se cumprisse a legislação da Polícia Feminina, "especialmente no que concerne ao relacionamento de intimidade entre policiais militares de círculos diferentes e, de maneira muito especial e séria entre policiais militares e policiais militares femininos, quando o envolvimento afetivo comprometa a imagem da Corporação (...)”. ${ }^{38}$ Como legítimo representante da instituição, ele reconhece o ideal de comportamento feminino vigente na década de 1970, bem como as transgressões disciplinares que ordenam o padrão de comportamento feminino descrito na legislação. Observa-se que a necessidade de controle sobre o comportamento das policiais permaneceu até o final do século XX, principalmente no que se refere aos relacionamentos entre policiais de círculos

37POLICIA MILITAR DO ESTADO DO PARANÁ. Estudo de Estado Maior n. 02/86. Ponta Grossa, 5 de maio de 1986.

${ }^{38}$ POLICIA MILITAR DO ESTADO DO PARANÁ. Boletim Geral n. 194, 1999. 
de poder diferentes, pois esses relacionamentos afetavam a ordem disciplinar e a hierarquia institucional.

\section{Entre a boa moça e a transgressora: reflexões finais}

Com a criação da Polícia Feminina, a instituição iniciou a constituição de uma identidade para a policial feminina e de um espaço feminino dentro da instituição masculina. Fato que produziu tensões e contradições, com a presença feminina. Uma existência que tendeu a reafirmar a identidade institucional masculina, mas também rompeu com essa identidade. A subordinação da Polícia Feminina e das agentes aos oficiais (homens) marcava o domínio masculino, colocando a instituição como um espaço da masculinidade. Os homens são aqueles que comandam. Porém, a existências da Polícia Feminina e a presença de mulheres usando a farda, vestimenta identificadora da instituição e de seus agentes, rompia com a ordem estabelecida. O espaço do quartel e a farda deixaram de ser uma exclusividade masculina. Portanto, a presença das mulheres na Polícia Militar do Paraná é uma contradição, que reproduz e rompe com o domínio masculino.

Vale destacar que as mulheres que ingressaram na Polícia Feminina já transgrediam o ideal de boa moça, ao escolherem uma "profissão de homem". Assim, embora a instituição estabelecesse um ideal de comportamento feminino conservador, a presença de mulheres na instituição militar era uma ruptura com o conservadorismo do espaço institucional vinculado aos espaços de poder ocupados pelas mulheres na sociedade. Visando amenizar as contradições observadas e vivenciadas por homens e mulheres no espaço institucional, a instituição utilizou a legislação e a vigilância como aparatos construtores de um padrão de comportamento para as policiais, os quais reproduzem um comportamento feminino conservador. Um padrão de comportamento que, além de constituir e reproduzir diferenças que subordinam o feminino ao masculino - na ordem institucional e no controle sobre as atitudes das agentes -, estabeleceu diferenças entre as policiais disciplinadas e as indisciplinadas e entre as policiais femininas e as mulheres civis.

A disciplina se constitui em uma ferramenta que instaura a ordem e utiliza a contradição e a diferença para delimitar as fronteiras entre o masculino e o feminino, o civil e o militar, a moral e o imoral, o normal e o anormal, mas também demarca fronteiras entres as diferentes feminilidades e masculinidades que constituem a instituição e objetiva orientar o comportamento dos agentes. O posicionamento da instituição no que se refere à conduta das mulheres policiais recria uma ordem tradicional que vincula a sexualidade feminina à honra masculina; no caso, a honra institucional. Ao vestirem a farda, as mulheres entraram em um espaço de poder masculino, mas não alteram a ordem existente. A farda é um símbolo da masculinidade e de poder. 


\section{Referências bibliográficas}

ANDERSON, Benedict. Comunidades imaginadas: reflexões sobre a origem e expansão do nacionalismo. Lisboa: Edições 70, 1991.

BEATTIE, Peter. Ser homem pobre, livre e honrado: a sodomia e os praças nas Forças Armadas brasileiras (1860-1930). In: CASTRO, Celso; IZECKSON, Vitor; KRAAY, Hendrik. Nova história militar brasileira. Rio de Janeiro: Editora FGV, 2004. p.269-299.

BOURDIEU, Pierre. A dominação masculina. Rio de Janeiro: Bertrand Brasil, 2007.

BOURDIEU, Pierre. O poder simbólico. Rio de Janeiro: Bertrand Brasil, 1998.

BRETAS, Marcos Luis; ROSEMBERG, André. A história da Polícia no Brasil: balanço e perspectiva. Topoi, Rio de Janeiro, vol. 14, n. 26, p.162-173, jan./jun. 2013.

CALAZANS, Marcia. A constituição de mulheres em policiais: um estudo sobre policiais femininas na Brigada Militar do Rio Grande do Sul. Dissertação (Mestrado em Psicologia), Universidade Federal do Rio Grande do Sul. Porto Alegre, 2003.

CAPPELLE, Mônica. O trabalho feminino no policiamento operacional: subjetividade, relações de poder e gênero na oitava região da Polícia Militar de Minas Gerais. Tese (Doutorado em Administração), Universidade Federal de Minas Gerais. Belo Horizonte, 2006.

CASTRO, Celso. Revoltas de soldados contra a República. In: CASTRO, Celso; IZECKSON, Vitor; KRAAY, Hendrik. Nova história militar brasileira. Rio de Janeiro: Editora FGV, 2004. p.301-114. CONNELL, Robert. La organización social de la masculinidad. In: VALDÉS, Teresa.; OLAVARRÍA, José. (Ed.). Masculinidad/es: poder y crisis. Santiago, Chile: Ediciones de las mujeres, n. 24, p. 31-48, 1997.

CONNELL, Robert. Políticas da masculinidade. Educação e Realidade, vol. 20, n. 2, p.185-206, 2005. FOUCAULT, Michel. Vigiar e punir. Petrópolis, RJ: Vozes, 1989.

LANNA, Mario. Jr. Tenentismo e crise política na Primeira República. In: FERREIRA, Jorge; DELGADO, Lucília. (Org.). O Brasil Republicano - o tempo do liberalismo excludente: da Proclamação da República à Revolução de 1930. Rio de Janeiro: Civilização Brasileira, 2006. p.313-350.

MCCANN, Frank. A revolta dos sargentos. In: MCCANN, Frank. Os soldados da pátria: história do Exército Brasileiro 1889-1937. São Paulo: Companhia das Letras, 2007. p.232-233.

MOREIRA, Rosemeri. "Entre o escudo de minerva e o manto de Penélope": a inclusão de mulheres na Polícia militar do Estado do Paraná (1975-1981). Dissertação (Mestrado em História), Universidade Estadual de Maringá. Maringá, 2007.

MOREIRA, Rosemeri. Sobre mulheres e polícias: a construção do policiamento feminino em São Paulo (1955-1964). Tese (Doutorado em História), Universidade Federal de Santa Catarina. Santa Catarina, 2011.

RAGO, Margareth. Trabalho feminino e sexualidade. In: PRIORI, M. História das mulheres no Brasil. São Paulo: Contextos, 2008. p.578-606.

REZENDE, Maria J. A ditadura militar no Brasil: repressão e pretensão de legitimidade (1964-1984). Londrina: Ed. UEL, 2001.

ROSA, João. Campanha do Contestado. Curitiba, PR: Associação da Vila Militar, 1998a.

ROSA, João. Combate do Irani. Curitiba, PR: Associação da Vila Militar, 1998b.

ROSA, João. Epopeia da Lapa: ação heroica da Polícia Militar do Paraná em defesa do regime republicano (1893-1894). Curitiba, PR: Associação da Vila Militar, 1999.

ROSA, João. Guerra do Paraguai. Curitiba, PR: Associação da Vila Militar, 2000.

ROSA, João. Revolução de 1924. Curitiba, PR: Associação da Vila Militar, 2001.

ROSA, João. Revolução de 1930. Curitiba, PR: Associação da Vila Militar, 2002.

ROSA, João. Revolução de 1932. Curitiba, PR: Associação da Vila Militar, 2004.

SCHACTAE, Andréa. Fardas e batons, armas e sais: a construção da Polícia Militar Feminina no Paraná(1977-2000). Tese (Doutorado em História), Universidade Federal do Paraná. Curitiba, 2011. SCOTT, Joan. Gênero: uma categoria útil de análise história. Educação e Realidade, vol. 2, n. 20, p.71-99, 1995.

SOARES, Barbara; MUSUMECI, Leonarda. Mulheres policiais: presença feminina na Polícia Militar do Rio de Janeiro. Rio de Janeiro: Civilização Brasileira, 2005. 